\title{
Húmus de minhoca associado a composto orgânico para a produção de mudas de tomate
}

Josimar Rodrigues Oliveira ${ }^{1}$

Fernando Bruno Xavier ${ }^{2}$

Neimar de Freitas Duarte ${ }^{3}$

\section{Resumo}

O objetivo deste trabalho é avaliar o potencial da utilização de composto orgânico associado a húmus de minhoca na produção de mudas de tomate. $O$ experimento foi conduzido sob cultivo protegido, no Instituto Federal de Minas Gerais, campus Bambuí. O Delineamento experimental utilizado foi inteiramente casualizado, com sete tratamentos e vinte e cinco repetições. Os tratamentos utilizados foram: T1 - Substrato comercial à base de fibra de coco e eucalipto (SC); T2 - 50\% SC $+25 \%$ de Composto orgânico (CO) $+25 \%$ Húmus de minhoca (HM); T3 - 25\% SC + 50\% CO + $25 \% \mathrm{HM}$; T4 - 25\% SC + 25\% CO + 50\% HM; T5 - 50\% CO + 50\% HM; T6 - 100\% HM e T7 - 100\% CO. Os parâmetros avaliados mostraram que a adição de diferentes proporções de composto orgânico associado ao húmus de minhoca no substrato comercial melhoram de forma significativa as suas propriedades químicas e físicas, promovendo melhor aeração, melhor retenção de água e uma disponibilidade de nutrientes durante esta fase inicial. Houve uma resposta linear em relação a adição destes materiais orgânicos ao substrato comercial, de forma que tanto o composto orgânico quanto o húmus de minhoca tem potencial para serem utilizados de forma pura como substrato para a produção de mudas de tomate. Apesar do bom crescimento das mudas nestes tratamentos, os nutrientes disponibilizados pelo substrato não são suficientes para suprir a demanda inicial da cultura, sendo necessário realizar uma adubação complementar de crescimento durante a fase de produção de mudas.

Palavras-chave: Sistemas agroecológicos. Lycopersicum esculentum. Compostagem. Substrato. Nutrição.

\section{Introdução}

A horticultura brasileira é um setor do agronegócio que garante renda e sustento para inúmeras famílias. A importância econômica de culturas como tomate, pimentão, batata, cenoura, alho, entre outras, é destaque no produto interno bruto de muitos estados do país como Minas Gerais, Goiás e São Paulo.

De acordo com dados da Associação Brasileira de Comércio de Sementes e Mudas - ABCSEM (2012), a horticultura é responsável por 2,4 milhões de empregos diretos, o que se traduz em 3,5 empregos por hectare. Dentre as principais culturas de impacto econômico pode-se destacar a tomaticultura. Estima-se que anualmente são produzidas mais de 3 milhões de toneladas de tomate

Universidade Federal de Viçosa (UFV), josimarodrigues@yahoo.com.br

2 Instituto Federal de Educação, Ciência e Tecnologia de Minas Gerais (IFMG), campus Bambuí, fernandomx2@gmail.com

3 Instituto Federal de Educação, Ciência e Tecnologia de Minas Gerais (IFMG), campus Bambuí, neimar@ifmg.edu.br 
no Brasil e que sua cadeia produtiva gere cerca de 300 mil empregos, movimentando, em termos de mão de obra, o montante de $\mathrm{R} \$ 280$ milhões (ABCSEM, 2012).

No cultivo do tomate, seja ele destinado para a indústria ou para o cultivo de mesa, é de suma importância a produção de mudas de qualidade. Uma boa muda começa por um bom substrato. Os substratos devem ser livres de fitopatógenos e sementes de plantas indesejáveis, bem como devem ser compostos por materiais de baixo custo, fácil aquisição, longa durabilidade e recicláveis, ou ainda desenvolverem métodos para reaproveitamento e melhoria das condições químicas e físicas do solo (SASSAKI, 1997; FACHINELLO et al., 2005).

Araújo Neto et al. (2009) afirmam que é praticamente impossível encontrar um substrato com todas as características desejáveis, sendo portanto, necessário misturar vários materiais para se conseguir um substrato próximo ao ideal. Na agricultura convencional, utilizam-se comumente os substratos comerciais à base de fibras vegetais e vermiculita expandida, sendo utilizados como fonte de nutrição para as mudas adubos de liberação lenta ou adubações foliares via irrigação.

$\mathrm{Na}$ agricultura ecológica e orgânica, a sustentabilidade dos sistemas agrícolas é fator primordial, e a integração de vários sistemas implicará no melhor aproveitamento de recursos disponíveis em uma propriedade, ocasionando assim um aporte maior de nutrientes para as plantas (BELÉM et al., 2006).

Na produção orgânica de mudas, diversos materiais considerados residuários disponíveis na propriedade podem ser alternativas para a utilização como substrato, como por exemplo, a maravalha, a casca de arroz, a cama de frango, o sabugo de milho triturado, o esterco bovino, palhadas vegetais, entre outros. Para tanto, são necessárias observações quanto às características químicas e físicas destes materiais, além de sua interação com as plantas.

O húmus de minhoca pode ser uma ótima alternativa de incremento para o substrato comercial em sistema de produção orgânico, visto que não é permitida a nutrição das mudas com adubos minerais solúveis. Aquino e Loureiro (2004) destacam que o húmus de minhoca constitui um excelente fertilizante orgânico capaz de melhorar atributos químicos, físicos e biológicos do solo, podendo ser utilizado também para a produção de mudas. Araújo Neto et al. (2009) também citam que o húmus de minhoca, por ser rico em fósforo, cálcio e potássio, pode fazer parte da composição de substratos para produção de mudas orgânicas.

Vários autores têm observado eficiência de diferentes substratos à base de húmus. Trabalhos realizados por Carijó et al. (2004), relatam que a utilização de substratos orgânicos no cultivo do tomate possibilitou produção de alta qualidade. Resultados semelhantes foram obtidos por outros autores quando avaliaram substratos orgânicos em ambiente protegido na cultura do tomate e outras olerícolas (FERNANDES et al., 2002; BELÉM et al., 2006; DINIZ et al., 2006; SILVA et al., 2007).

Neste contexto, o objetivo deste trabalho é avaliar o potencial da utilização de composto orgânico associado a húmus de minhoca na produção de mudas de tomate.

\section{Material e Métodos}

O experimento foi conduzido na unidade educativa de produção Agricultura I, sob cultivo protegido, no Instituto Federal de Educação, Ciência e Tecnologia de Minas Gerais, campus Bambuí. $\mathrm{O}$ delineamento experimental utilizado foi inteiramente casualizado, com sete tratamentos e vinte e cinco repetições. Os tratamentos utilizados são apresentados na Tabela 1. 
Tabela 1. Tratamentos avaliados para a produção de mudas de tomate.

\begin{tabular}{c|c}
\hline Identificação $^{*}$ & Tratamento (Substrato formulado) \\
\hline T1 & Substrato comercial à base de fibra de coco e eucalipto (SC) \\
T2 & $50 \%$ SC $+25 \%$ de Composto orgânico (CO) $+25 \%$ Húmus de minhoca (HM) \\
T3 & $25 \% \mathrm{SC}+50 \% \mathrm{CO}+25 \% \mathrm{HM}$ \\
T4 & $25 \% \mathrm{SC}+25 \% \mathrm{CO}+50 \% \mathrm{HM}$ \\
T5 & $50 \% \mathrm{CO}+50 \% \mathrm{HM}$ \\
T6 & $100 \% \mathrm{HM}$ \\
T7 & $100 \% \mathrm{CO}$ \\
\hline
\end{tabular}

${ }^{*} \mathrm{~T} 1, \mathrm{~T} 2, \mathrm{~T} 3$ até T7 são as codificações designadas para identificar cada tipo de tratamento (substrato formulado).

Fonte: Elaboração própria.

O composto orgânico utilizado foi preparado durante um ano e meio, utilizando-se $20 \%$ de palhada de tifton $+80 \%$ de esterco bovino. Desde o início do processo de compostagem o material foi irrigado com efluente líquido de biodigestor da granja de suínos do campus e realizava-se o revolvimento da pilha a cada três dias.

O húmus de minhoca foi obtido no setor de minhocultura do IFMG, campus Bambuí. Para o processo de humificação, o esterco bovino foi acondicionado em minhocários retangulares com dimensão de $1 \mathrm{~m}$ de largura $\times 4 \mathrm{~m}$ de comprimento, com cobertura tipo túnel com plástico e sombrite $50 \%$ inoculados com Elisenia andrei. O composto e o húmus foram peneirados em malha de $8 \mathrm{~mm}$ e incorporados manualmente ao substrato comercial conforme as proporções indicadas.

Foram utilizadas as sementes de tomate Santa Cruz Kada Gigante, com 91\% de germinação e pureza de 99,9\%, sendo semeadas em bandejas de poliestireno expandido com 128 células, colocando-se duas sementes por célula. As mudas não receberam adubação complementar e foram irrigadas diariamente de forma uniforme para manter a umidade adequada à germinação e ao desenvolvimento das mudas. Aos 7 dias após o plantio foi realizada avaliação da porcentagem de emergência e realizou-se o desbaste, deixando apenas uma planta por célula.

Aos 15 dias pós-semeadura foram mensurados altura das mudas, número de folhas e comprimento radicular. Após estas avaliações, as mudas foram lavadas em água corrente para a retirada do substrato e separadas em parte aérea e raiz para analisar o peso da matéria seca. As partes foram colocadas em sacos de papel Kraft devidamente identificados conforme o tratamento e levadas à estufa de circulação forçada de ar, na temperatura de $65 \pm 1^{\circ} \mathrm{C}$. Após atingir o peso constante foram pesadas em balança analítica no laboratório multidisciplinar de biologia.

Os dados foram submetidos à análise de variância e teste de Tukey a 5\% de probabilidade, através do programa estatístico SISVAR 5.3 (FERREIRA, 2010).

\section{Resultados e Discussões}

A adição de materiais orgânicos ao substrato para o cultivo de mudas de plantas olerícolas é benéfico, visto que este pode melhorar as características físicas do material, além de incrementar a nutrição das plantas com a liberação de nutrientes. Este fato pode ser observado para a produção de mudas de tomate (Figura 1 ). 
Figura 1. Altura das plântulas de tomate aos 15 dias após a semeadura. Bambuí, 2011.

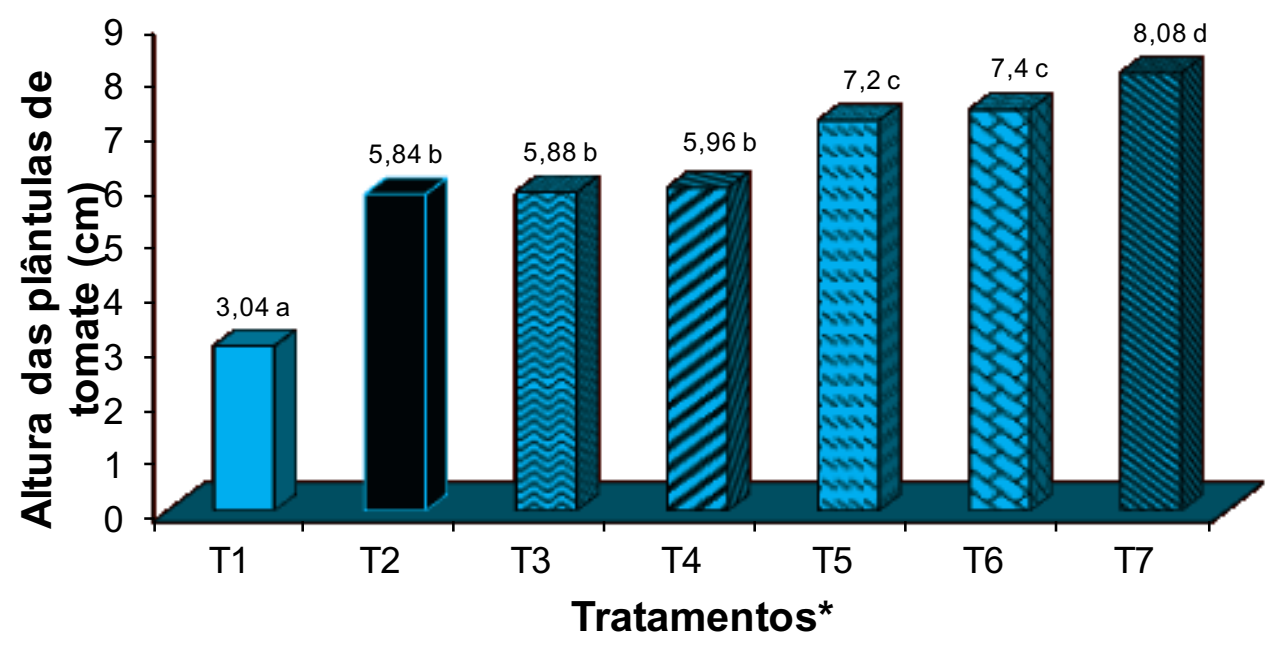

* T1 - Substrato comercial à base de fibra de coco e eucalipto (SC); T2 - 50\% SC + $25 \%$ de Composto or-
gânico (CO) + 25\% Húmus de minhoca (HM); T3 - 25\% SC + 50\% CO + 25\% HM; T4 - 25\% SC + 25\%
CO + 50\% HM; T5 - 50\% CO + 50\% HM; T6 - 100\% HM e T7 - $100 \%$ CO.

Fonte: Elaboração própria

As plântulas cultivadas apenas no substrato comercial apresentaram um desenvolvimento muito inferior em relação àquelas às quais se adicionou o material orgânico. Houve diferenças estatísticas entre os tratamentos, pelo Teste de Tukey $(p<0,05)$. A adição de $25 \%$ de composto orgânico com 25\% de húmus de minhoca (T2) apresentou incremento significativo na altura, em relação ao uso do substrato comercial (T1) e foi estatisticamente similar ao desenvolvimento das proporções testadas nos tratamentos T3 e T4.

Apenas o uso do composto orgânico com o húmus de minhoca (T5) já foi suficiente para produzir mudas com altura cerca de $4 \mathrm{~cm}$ maiores do que quando se utilizou apenas o substrato comercial (Figura 1). 0 uso apenas do húmus de minhoca como substrato (T6) foi estatisticamente similar à mistura utilizada no T5 para o parâmetro altura, tendo-se o tratamento com $100 \%$ de composto orgânico (T7) se destacado por promover o melhor crescimento. Andreani Júnior et al. (2011) também observaram maior altura de mudas de tomate cereja produzidas em substrato de composto à base de palhada de gramíneas.

Quando avaliado o número de folhas, o padrão de resposta foi bem similar (Figura 2), pode-se observar que o composto orgânico utilizado como substrato (T7) apresenta maior número de folhas em relação aos demais tratamentos, entretanto apresenta similaridade estatística com o número de folhas apresentado pelo húmus de minhoca (T5). Todos os tratamentos em que se adicionou certa proporção de material orgânico ao substrato comercial apresentaram maior número de folhas. 
Figura 2. Número de folhas das plântulas de tomate aos 15 dias após a semeadura. Bambuí, 2011.

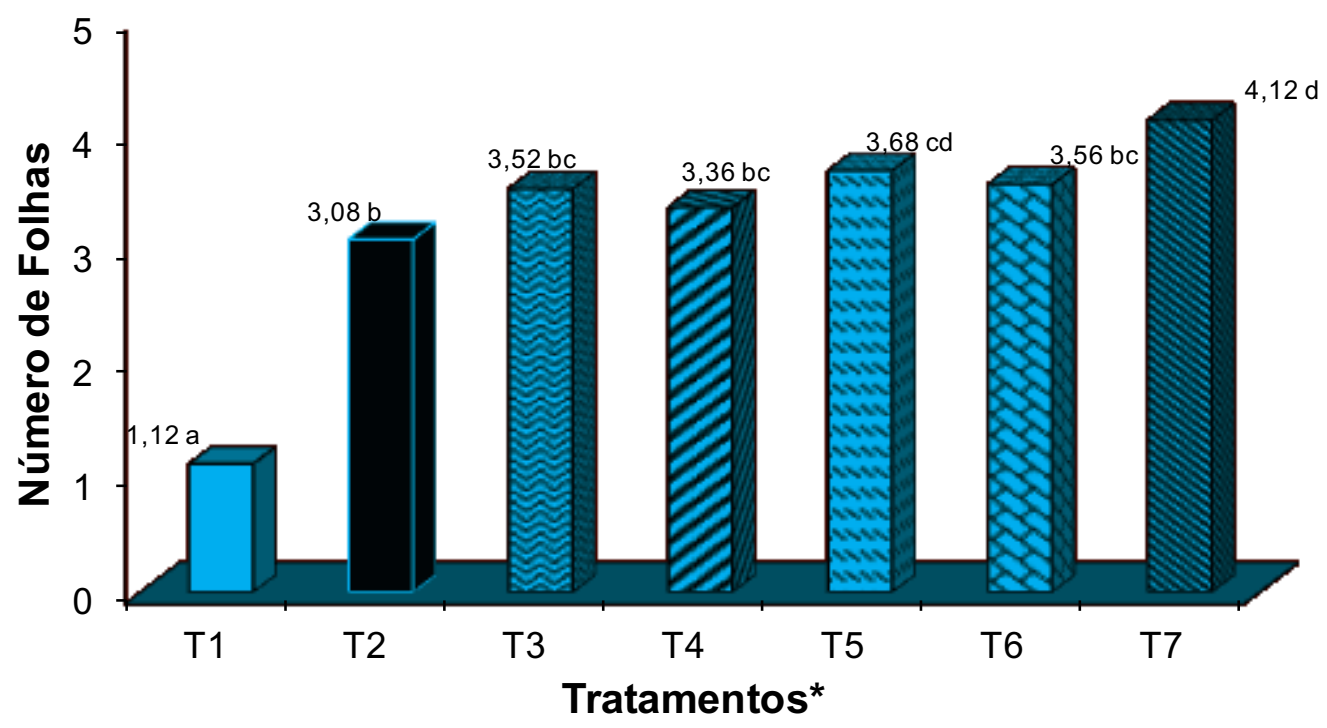

\footnotetext{
* T1 - Substrato comercial à base de fibra de coco e eucalipto (SC); T2 - 50\% SC + $25 \%$ de Composto orgânico (CO) + 25\% Húmus de minhoca (HM); T3 - 25\% SC + 50\% CO + 25\% HM; T4 - 25\% SC + 25\% $\mathrm{CO}+50 \% \mathrm{HM} ; \mathrm{T} 5-50 \% \mathrm{CO}+50 \% \mathrm{HM} ; \mathrm{T} 6-100 \% \mathrm{HM}$ e T7 - $100 \% \mathrm{CO}$.
}

Fonte: Elaboração própria

Em relação ao comprimento radicular, as mudas que se desenvolveram no substrato comercial (T1) apresentaram aproximadamente $3 \mathrm{~cm}$ a menos de raiz em relação àquelas que tiveram material orgânico incorporado ao substrato, como pode ser visualizado na Figura 3. 0 tratamento T7 apresentou de forma significativa um maior comprimento de raiz em relação aos tratamentos T2 e T3. Os tratamentos T4, T5, T6 e T7 apresentaram desenvolvimento radicular similares, o que indica que a simples adição de $25 \%$ de composto orgânico com $50 \%$ de húmus já é suficiente para melhorar a estrutura do substrato. Diniz et al. (2006) também observaram que o húmus tem grande potencial para ser utilizado como substrato para a produção de mudas de tomate, obtendo-se os melhores resultados quando este foi acrescido de $40 \%$ de vermiculita.

Não são liberadas quantidades suficientes de nutrientes para a produção de mudas vigorosas com o padrão de plantio e comercialização estipulados pelo mercado, no entanto pode favorecer o melhor desenvolvimento das plântulas e reduzir o número de adubações necessárias para a produção de mudas de tomate. Na Tabela 2 são apresentados os resultados referentes à matéria seca da parte aérea e matéria seca de raiz, onde pode ser observado que os maiores incrementos foram obtidos na presença de composto orgânico e húmus de minhoca, sendo que ambos os materiais podem ser utilizados "in natura" para a produção de mudas de tomate, ou seja, tanto o composto quanto o húmus constituem ótimos substratos. Godoy e Farinacio (2007) destacam que além de exercer a função de suporte às plantas, o substrato deve proporcionar adequado suprimento de ar e água ao sistema radicular, ser isento de fitopatógenos, de fácil manejo, baixo custo, alta disponibilidade e ter longa durabilidade. Estas características foram observadas para os tratamentos avaliados, em especial para o T7 
Figura 3. Comprimento radicular das plântulas de tomate aos 15 dias após a semeadura, nos diferentes substratos. Bambuí, 2011.

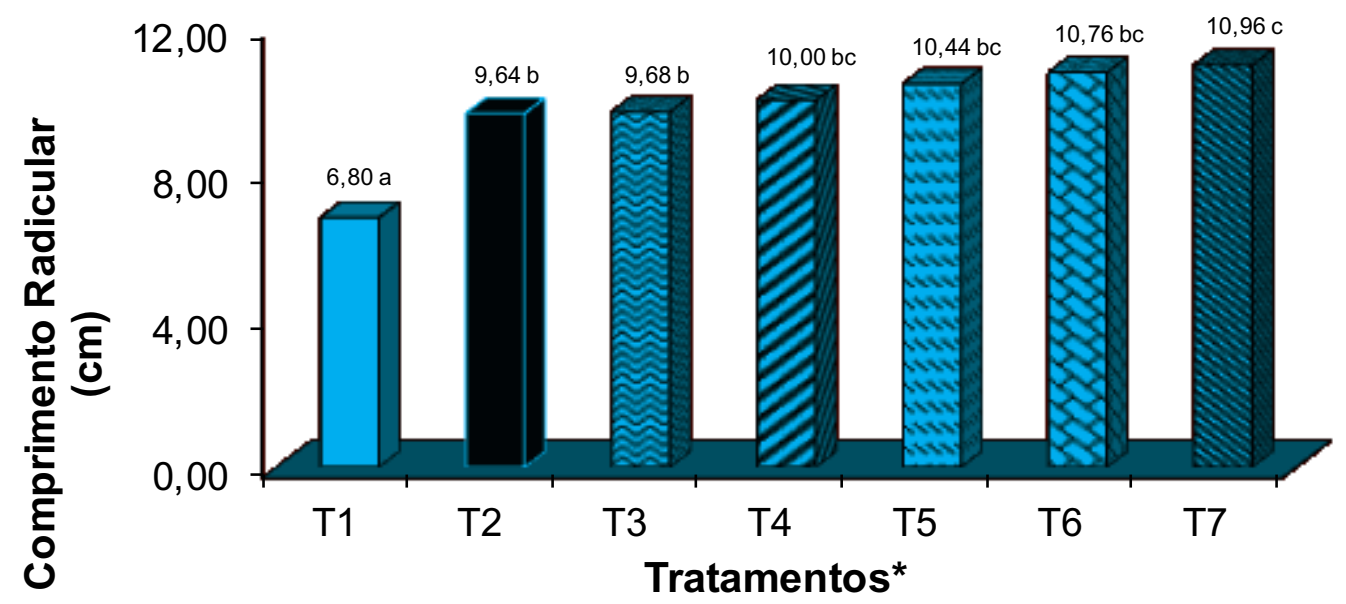

* T1 - Substrato comercial à base de fibra de coco e eucalipto (SC); T2 - 50\% SC + $25 \%$ de Composto orgânico (CO) + 25\% Húmus de minhoca (HM); T3 - 25\% SC + 50\% CO + 25\% HM; T4 - 25\% SC + 25\% $\mathrm{CO}+50 \% \mathrm{HM} ; \mathrm{T} 5-50 \% \mathrm{CO}+50 \% \mathrm{HM} ; \mathrm{T} 6-100 \% \mathrm{HM}$ e T7 $-100 \% \mathrm{CO}$.

Fonte: Elaboração própria

Tabela 2. Matéria seca da parte aérea, radicular e total das mudas de tomate produzidas nos diferentes substratos.

\begin{tabular}{cccc}
\hline${ }^{1 /}$ Tratamentos & $\begin{array}{c}\text { Matéria seca da parte } \\
\text { aérea (MSA) }\end{array}$ & $\begin{array}{c}\text { Matéria seca de raiz } \\
\text { (MSR) }\end{array}$ & Matéria seca total (MST) \\
\hline T1 & $0,22 \mathrm{a}$ & $0,07 \mathrm{a}$ & $0,29 \mathrm{a}$ \\
T2 & $1,56 \mathrm{~b}$ & $0,28 \mathrm{~b}$ & $1,84 \mathrm{~b}$ \\
T3 & $1,75 \mathrm{c}$ & $0,30 \mathrm{c}$ & $2,05 \mathrm{c}$ \\
T4 & $1,88 \mathrm{~d}$ & $0,36 \mathrm{~d}$ & $2,24 \mathrm{~d}$ \\
T5 & $2,46 \mathrm{e}$ & $0,42 \mathrm{e}$ & $2,88 \mathrm{e}$ \\
T6 & $2,60 \mathrm{f}$ & $0,50 \mathrm{f}$ & $3,10 \mathrm{f}$ \\
T7 & $3,38 \mathrm{~g}$ & $0,58 \mathrm{~g}$ & $3,96 \mathrm{~g}$ \\
\hline
\end{tabular}

${ }^{1 / T 1}$ - Substrato comercial à base de fibra de coco e eucalipto (SC); T2 - 50\% SC $+25 \%$ de Composto orgânico (CO) + 25\% Húmus de minhoca (HM); T3 - 25\% SC + 50\% CO + 25\% HM; T4 - 25\% SC + 25\% $\mathrm{CO}+50 \% \mathrm{HM} ; \mathrm{T} 5-50 \% \mathrm{CO}+50 \% \mathrm{HM} ; \mathrm{T} 6-100 \% \mathrm{HM}$ e T7 $-100 \% \mathrm{CO}$.

Fonte: Elaboração própria

A maior vantagem na utilização deste tipo de material como substrato está na facilidade de obtenção da matéria prima para realizar o processo de compostagem ou humificação, visto que há grande disponibilidade de esterco, advindo de atividades pecuárias como a criação de suínos e gado leiteiro. Os procedimentos, tanto para a compostagem quanto para a obtenção de húmus, têm custos relativamente baixos e como o material final apresenta qualidade para ser utilizado como substrato 
comercial, há uma redução no custo de produção da lavoura de tomate, uma vez que o produtor rural poderá substituir o substrato comercial por um substrato confeccionado com materiais da própria fazenda. Outro ganho importantíssimo é o aspecto do aproveitamento dos resíduos gerados por outras atividades da fazenda na produção agrícola. O esterco que anteriormente poderia se tornar um problema ambiental acaba retornando para o sistema de produção na forma de substrato e com potencial de utilização até mesmo na implantação de lavouras como adubo orgânico.

\section{Conclusões}

O composto orgânico e o húmus de minhoca podem ser utilizados como substrato para produzir mudas de tomate. Ambos podem substituir o substrato comercial e assim reduzir o custo da lavoura.

É importante complementar a nutrição das mudas por meio de fertilizantes, sejam eles via irrigação, solução nutritiva ou grânulos de liberação lenta, visto que os nutrientes fornecidos pela composição do substrato não são suficientes para produzir mudas com padrão comercial.

\section{Earthworm castings associated organic compost to tomato seedlings production}

\section{Abstract}

The objective of this work was to evaluate the potential of use of organic compound associated with earthworm castings in the production of tomato seedlings. The experiment was carried under greenhouse conditions at Instituto Federal Minas Gerais, campus Bambuí. This work was developed in completely randomized experimental design, with seven treatments and twenty-five repetitions. The treatments were: T1 - Commercial substrate of the coconut fiber and eucalyptus (SC); T2 $50 \%$ SC $+25 \%$ Organic compound (CO) $+25 \%$ Earthworm castings (HM); T3 - 25\% SC + 50\% $\mathrm{CO}+25 \% \mathrm{HM} ; \mathrm{T} 4-25 \% \mathrm{SC}+25 \% \mathrm{CO}+50 \% \mathrm{HM}$; T5 - 50\% CO + 50\% HM; T6 - 100\% HM e T7 - 100\% CO. The evaluated parameters showed that the addition of different ratios of organic compound associated with earthworm humus in the commercial substrate significantly improves its physical and chemical properties, providing better aeration, improved water retention and availability of nutrients during this initial phase. There was a linear response with respect to the addition of these organic materials with the commercial substrate, so that both the organic and the post with earthworm humus have the potential to be used in pure form as a substrate for the production of tomato seedlings. Despite the good growth of seedlings in these treatments, the nutrients provided by the substrate are not sufficient to meet the initial demand of culture, thus being necessary to undertake a fertilizer supplement growth during the seedling production.

Key-words: Agroecosystems. Lycopersicum esculentum. Composting. Substrate. Nutrition.

\section{Referências Bibliográficas}

ABCSEM - Associação Brasileira do Comércio de Sementes e Mudas. Tomaticultura: valioso segmento do agronegócio nacional. 2012. Disponível em: <http://www.abcsem.com.br/noticia. php?cod=2420 > . Acessado em: 20 de Mar. 2012 
ANDREANI JÚNIOR, R.; ANDREANI, D. I. K.; LUISON, E. A.; SILVA, E. G.; GIMENEZ, J. I. Diferentes compostos orgânicos como substrato para a produção de mudas de tomate. Pesquisa em Foco, São Luís, v. 19, n.1, p. 42-52, 2011.

AQUINO, A. M.; LOUREIRO, D. C. Minhocultura. Embrapa Agrobiologia. Seropédica, RJ, 2004.

ARAúJo Neto, S. E.; AZEVEdO, J. M. A.; GALVÃO, R. O.; OLIVEIRA, E. B. L.; FERREIRA, R. L. F. Produção de muda orgânica de pimentão com diferentes substratos.Ciência Rural, Santa Maria, v. 39, n. 5, p. 1408-1413, ago. 2009.

BELÉM, T. P.; MEDEIROS, D. C.; SILVEIRA, C. M.; AZEVEDO, B.; MOREIRA, J. N.; NASCIMENTO, C. F.; PINHEIRO, M. D. C.; DANTAS, M. R. S.; SANTOS, S. C. L.; MARQUES, L. F.; CÂMARA, M. J. T. Avaliação da qualidade de mudas de pimentão em diferentes substratos utilizando efluentes de piscicultura e água de poço tubular, em sistema orgânico. UFERSA: Mossoró, RN, 2006.

CARIJO, O. A., VIDAL, M. C., REIS, N. V. B. dos . Produtividade do tomateiro em diferentes substratos e modelos de casas de vegetação. Horticultura Brasileira. Brasília, , v. 22, n. 1, p. 5-9, jan./mar.2004.

DINIZ, K. A.; GUIMARÃES, S. T. M. R.; LUZ, J. M. Q. Húmus como substrato para a produção de mudas de tomate, pimentão e alface. Bioscience Journal, Uberlândia, v. 22, n. 3, p. 63-70, set./ dez. 2006.

FACHINELLO, J. C. et. al. Propagação de plantas frutíferas. Brasília: Embrapa, 2005. 221p.

FERNANDES, C., ARAUJO, J. A. C.; CORA, J. E. Impacto de quatro substratos e parcelamento da fertirrigação na produção de tomate sob cultivo protegido. Horticultura Brasileira, dez. 2002, v. 20, n. 4, p.559-563.

FERREIRA, D. F. SISVAR 5.3. Sistema de Análises Estatísticas. Lavras: UFLA, 2010.

GODOY, W.; FARINACIO, D. Comparação de substratos alternativos para a produção de mudas de tomateiro.Revista Brasileira de Agroecologia, Cruz Alta, v. 2, n. 2, p. 1095-1098, out. 2007.

SASSAKI, O. K. Resultados preliminares da produção de hortaliças sem o uso de solo no Amazonas. Horticultura Brasileira, Brasília, v. 15, p. 165-169, 1997.

SILVA, S. S. da. et al. Produção orgânica de mudas de couve-manteiga em substratos à base de coprolito de minhocas.Caatinga, Mossoró, v. 20, n. 4, p. 78-83, 2007.

\section{Histórico editorial}

Recebido: 07/03/2013

Avaliação e copidesque: 11/03/2013 a 18/06/2013 